\title{
Avoiding pitfalls in interdisciplinary education
}

\author{
R. E. Holt ${ }^{1,11, *}$, P. J. Woods ${ }^{2,12}$, A. S. A. Ferreira ${ }^{3,13}$, H. Bardarson ${ }^{2,12}$, S. Bonanomi ${ }^{4,14}$, \\ W. J. Boonstra ${ }^{5}$, W. E. Butler ${ }^{2}$, F. K. Diekert ${ }^{6,15}$, N. Fouzai ${ }^{1}$, M. Holma ${ }^{7}$, A. Kokkalis ${ }^{3}$, \\ K. Ø. Kvile ${ }^{6,16}$, J. I. Macdonald ${ }^{2}$, E. Malanski ${ }^{3,17}$, E. Nieminen ${ }^{7,18}$, K. M. Ottosen ${ }^{8}$, \\ M. W. Pedersen ${ }^{3}$, A. Richter ${ }^{6,9}$, L. $\operatorname{Rogers}^{6}$, G. Romagnoni ${ }^{6}$, M. Snickars ${ }^{10}$, \\ A. Törnroos ${ }^{10}$, B. Weigel ${ }^{10}$, J. D. Whittington ${ }^{6}$, J. Yletyinen ${ }^{5}$ \\ ${ }^{1}$ Department of Biology, University of Bergen, PO Box 7803, 5020 Bergen, Norway \\ ${ }^{2}$ Faculty of Life and Environmental Sciences, University of Iceland, Askja, Sturlugata 7, 101 Reykjavík, Iceland \\ ${ }^{3}$ DTU Aqua, Kemitorvet Building 201, 2800 Kgs. Lyngby, Denmark \\ ${ }^{4}$ DTU Aqua, Vejlsøvej 39, 8600 Silkeborg, Denmark \\ ${ }^{5}$ Stockholm Resilience Centre, Stockholm University, Kräftriket 2B, 11419 Stockholm, Sweden \\ ${ }^{6}$ Centre for Ecological \& Evolutionary Synthesis, Department of Biosciences, University of Oslo, Postboks 1066, Blindern, \\ 0316 Oslo, Norway \\ ${ }^{7}$ Department of Economics and Management, University of Helsinki, PO Box 27, 00014 Helsinki, Finland \\ ${ }^{8}$ Faculty of Science \& Technology, The University of the Faroe Islands, Faculty of Science and Technology, Nóatún 3 , \\ 100 Tórshavn, Faroe Islands \\ ${ }^{9}$ Environmental Economics and Natural Resources Group, Wageningen University, PO Box 8130, 6700 EW Wageningen, \\ The Netherlands \\ ${ }^{10}$ Environmental and Marine Biology, Åbo Akademi University, Artillerigatan 6, Biocity, 20520 Turku/Åbo, Finland \\ ${ }^{11}$ Present address: Centre for Ecological \& Evolutionary Synthesis, Department of Biosciences, University of Oslo, \\ Postboks 1066, Blindern, 0316 Oslo, Norway \\ ${ }^{12}$ Present address: Marine and Freshwater Research Institute, Skulagata 4, 121 Reykjavik, Iceland \\ ${ }^{13}$ Present address: School of Oceanography, University of Washington, Seattle, WA 98195, USA \\ ${ }^{14}$ Present address: National Research Council (CNR), Institute of Marine Science (ISMAR), Largo Fiera della Pesca 1, 60125 Ancona, Italy \\ ${ }^{15}$ Present address: Department of Economics, Heidelberg University, Bergheimer Str. 20, 69115 Heidelberg, Germany \\ ${ }^{16}$ Present address: Department of Biology, Woods Hole Oceanographic Institution, Woods Hole, MA 02543, USA \\ ${ }^{17}$ Present address: Instituto Nacional da Mata Atlântica - INMA, Av. José Ruschi 4, PO Box 29650-000, Santa Teresa, ES, Brazil \\ ${ }^{18}$ Present address: Finnish Environment Institute (SYKE), PO Box 140, 00251 Helsinki, Finland
}

\begin{abstract}
As the world's social-environmental problems increasingly extend across boundaries, both disciplinary and political, there is a growing need for interdisciplinarity, not only in research per se, but also in doctoral education. We present the common pitfalls of interdisciplinary research in doctoral education, illustrating approaches towards solutions using the Nordic Centre for Research on Marine Ecosystems and Resources under Climate Change (NorMER) research network as a case study. We provide insights and detailed examples of how to overcome some of the challenges of conducting interdisciplinary research within doctoral studies that can be applied within any doctoral/postdoctoral education programme, and beyond. Results from a selfevaluation survey indicate that early-career workshops, annual meetings and research visits to other institutions were the most effective learning mechanisms, whereas single discipline-focused courses and coursework were among the least effective learning mechanisms. By identifying the strengths and weaknesses of components of NorMER, this case study can inform the design of future programmes to enhance interdisciplinarity in doctoral education, as well as be applied to science collaboration and academic research in general.
\end{abstract}

KEY WORDS: Climate change $\cdot$ Interdisciplinarity $\cdot$ Education $\cdot$ Learning mechanisms $\cdot$ Research network 


\section{INTRODUCTION}

\subsection{Interdisciplinarity}

There is an increasing need for doctoral students to train in settings that enhance interdisciplinarity, i.e. a learning environment that 'analyzes, synthesizes and harmonizes links between disciplines into a coordinated and coherent whole' (Alvargonzález 2011 , p. 388). The call for interdisciplinarity is indicative of the challenges facing scientists today, as the world's environmental problems, such as climate change, increasingly extend across boundaries, between disciplines and nations (Stenseth et al. 2005, Haapasaari et al. 2012).

Many academic and scientific institutions acknowledge the need for interdisciplinary education to prepare future scientists and managers to solve complex social-environmental issues (NIH 2009, NSF 2011, Shaman et al. 2013). However, prioritisation of interdisciplinary skills in doctoral education comes with trade-offs: not only should a successful early-career scientist become an expert in his/her academic field, but he/she should also demonstrate abilities to collaborate and gain international and interdisciplinary experience. As such, there is an ever-present struggle to develop mechanisms that support interdisciplinarity for doctoral students (Haider et al. in press).

As doctoral students and early-career scientists facing these challenges, we must make appropriate decisions to successfully address the demand for interdisciplinarity. In this paper, we share our perspective as early-career researchers faced with the task of achieving high-level interdisciplinary research within doctoral education.

We focus on whether interdisciplinarity can be achieved within doctoral education, using the Nordic Centre for Research on Marine Ecosystems and Resources under Climate Change (NorMER) as a case study, explored through a self-evaluation survey. We demonstrate how its structure and learning mechanisms helped us to overcome 5 well-recognised pitfalls (listed in Section1.2, below) to starting and conducting interdisciplinary research (Öberg 2009, Borrego \& Cutler 2010, Boden et al. 2011) whilst in doctoral education and as early-career researchers.

\subsection{Pitfalls to starting and conducting interdisciplinary research}

Disjointed communication. Additional time and resources are needed for understanding and commu- nicating unique vocabulary used across different disciplines (Morse et al. 2007, Öberg 2009, Borrego \& Cutler 2010). Due to time/funding constraints, the typical duration of doctoral programmes may not be conducive to conducting interdisciplinary research.

Absence of credibility frameworks. Working within 2 or more disciplines may mean conceptualising and undertaking research without pre-defined disciplinary frameworks of credibility (Öberg 2009, Boden et al. 2011).

Difficulty in identifying focal themes and audiences. A lack of guidance in the potential trade-off between depth versus breadth could result in interdisciplinary projects existing as disjointed 'add-ons' to disciplinary doctoral degrees. Although the number of interdisciplinary outlets has recently started to grow, there are still comparatively few, which may shift publications towards single-discipline studies (Öberg 2009, Boden et al. 2011, Shaman et al. 2013).

Dearth of evaluation methods for 'interdisciplinarity'. Desired learning outcomes and assessment methods may not be supported by learning activities (Borrego \& Cutler 2010). Interdisciplinary collaboration is frequently induced by department/faculty, rather than viewed as a transferable skill (Borrego \& Newswander 2011).

Lack of continuity. Due to a lack of continuity in formal institutional constructs (i.e. academia and other scientific pathways), interdisciplinary careers suffer from a lack of permanence and are constrained by limited funding in postdoctoral careers (Lyall et al. 2013, Bromham et al. 2016).

\subsection{A case study}

Climate change is a prime example of a complex interdisciplinary problem, with geological, atmospheric and oceanic changes, whose causes and consequences spread widely across environmental, biological, economic, and social fields (Stenseth et al. 2005, Mooney et al. 2013). Funding and performing an interdisciplinary approach is therefore essential to understanding and assessing climate change and its ecosystem impacts within the environment. However, experiences of implementing an interdisciplinary approach are limited. Each research network is then a trial to implement a programme that avoids the pitfalls outlined above.

NorMER was one such network. It encouraged interdisciplinarity through a variety of initiatives, including doctoral courses, specialised workshops, and networking techniques. NorMER PhD students 
and postdocs, with a variety of disciplinary backgrounds such as ecology, economics, fisheries and the social sciences, were employed across the 6 Nordic countries (Norway, Sweden, Finland, Denmark, Iceland and the Faroe Islands) (Fig. 1). First, 4 mo international placements were organised to foster collaboration, which included an additional mentor within the placement location, who worked in a different discipline to the PhD student. Second, during annual meetings, time was devoted to interactive sessions such as speed-talks, poster sessions, or discussion groups with peers and senior advisors/scientists. Emphasis was placed on a sequence of one-toone interactions, intended to expose doctoral students to multiple disciplines. Finally, resources were specifically provided for early-career workshops following annual meetings, which provided opportunity for brainstorming and developing manuscripts, thereby fostering independent peer collaborations.

However, despite the networking initiatives to increase interdisciplinarity, there were no formal methods used to evaluate interdisciplinary skills. Instead, internal feedbacks were developed for evaluating the organisation as a whole, through the creation of an external advisory panel and a channel where peers could voice concerns/problems. Although such lines of communication were found helpful in strengthening independent collaboration, it did not provide guidelines on how to achieve interdisciplinarity. As a result, we took advantage of early-career workshops to develop our own research questions and student-led initiatives in an attempt to develop interdisciplinarity through trial and error. The scientific publications Boonstra et al. (2015), Pedersen et al. (2016), and the present study are results of such student-led initiatives.

\section{METHODS}

\subsection{Indirect assessment method}

There are 2 principal educational assessment pathways: direct and indirect assessment. Direct assessment requires that students display what they've learned by 'doing', demonstrating how well they have mastered learning objectives, for example a published test, exam, or portfolio; whereas indirect assessment involves a report about learning rather than a direct demonstration of learning (Allen 2007). Indirect assessment methods include reflective essays and self-evaluation procedures, such as surveys, interviews and focus groups, that can clarify opinions and provide insight. In the case of interdisciplinarity, there are no direct assessment methods available

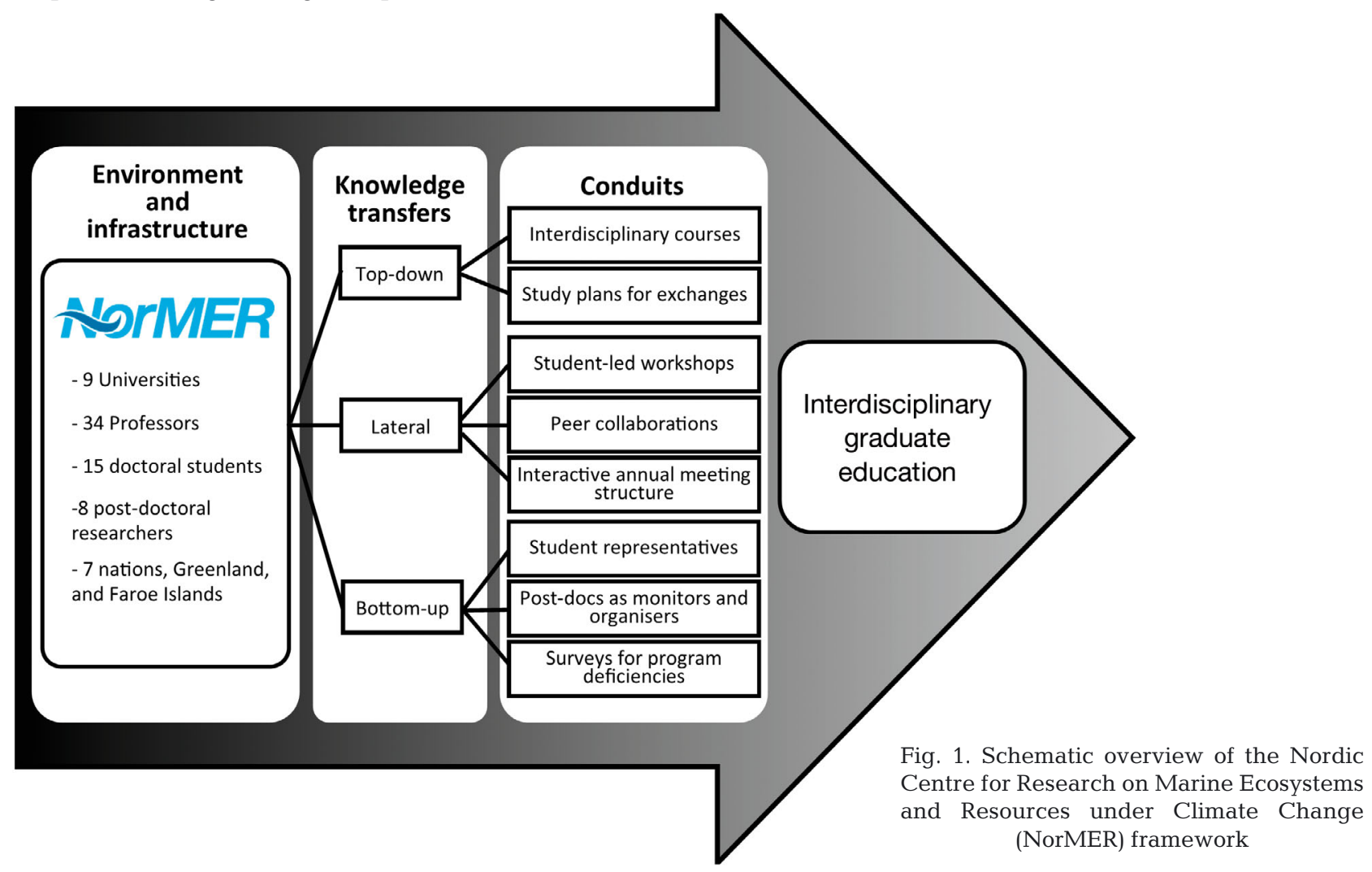


with which to assess the effectiveness of the learning mechanisms of the case study research network. We therefore use an indirect assessment method to evaluate the interdisciplinary learning outcomes of NorMER. We focus on a reflective self-evaluation survey that allows for retrospective reflection, and permits participants to evaluate their own work and progress in relation to the survey questions being asked. This indirect assessment approach allows insight into student perceptions, attitudes and decision-making, as well as the generation of unanticipated results that may not have been available through a direct assessment method.

\subsection{Survey development}

A self-evaluation survey was developed to assess NorMER within the context of interdisciplinarity. The survey included 53 items within 6 core sections (available in the Supplement at www.int-res.com/ articles/suppl/c074p121_supp.pdf), 4 of which assessed interdisciplinarity using a 5-point Likert-scale response format (Allen \& Seaman 2007, Lozano et al. 2008). In general, the Likert scale followed the following format: a score of $1=$ strong no, $2=$ weak no, 3 = neutral, $4=$ weak yes, and $5=$ strong yes (for question-specific Likert-scale responses, please see the original survey questions detailed in the Supplement). The null hypothesis of this study is no perceived effect of NorMER on achieving interdisciplinarity, i.e. an answer of 3 on the Likert scale. The survey was anonymous, and as such, the initial questions pertained to basic personal information and previous experience/interest in interdisciplinarity (Fig. 2), whereas the last section comprised further comments and an evaluation of the survey itself (see the Supplement). The main part of the survey (Sections II to V in the Supplement) was designed to analyse whether the 4 learning themes of interdisciplinarity identified by Manathunga et al. (2006) and Lattuca (2002) were addressed through NorMER. These themes (words in bold-retained as key words in Section 3) included: (1) communicating complex ideas between disciplines, (2) talking with scientists in other disciplines, (3) engaging with new methods or texts of another discipline, and (4) synthesising disciplinary knowledge to generate cre- ative methods or related criticism of single disciplines (see also Figs. $3 \& 4$ ). The second section in the survey evaluated the effectiveness of NorMER's various interdisciplinary learning initiatives in achieving these 4 learning themes. The third section comprised an evaluation of interdisciplinarity within the respondent's own research as an outcome of engagement in NorMER's educational programme (Mitchell \& Willetts 2009). The fourth section evaluated whether other interdisciplinary skills were attained as a result of this engagement (Spelt et al. 2009, Mitchell \& Willetts 2009).

The survey was administered via email on a voluntary basis, using an informed consent approach (Punch 2014). Survey instruction was conveyed to participants in clear understandable language and participation was not compulsory.

\section{RESULTS AND DISCUSSION}

\subsection{Participants}

Twenty-five early-career researchers participated in NorMER. Twenty-two completed the survey, giving an overall $88 \%$ response rate. The survey was re- 
presented by $14 \mathrm{PhD}$ students and 8 postdoctoral researchers, each at different stages within the NorMER programme: 1 at $50 \%, 9$ at $75 \%$ and 12 at $100 \%$ through a person's PhD/employment. The survey participants were represented by a 50:50 male to female ratio.

\subsection{Survey results}

The self-evaluation survey suggests that NorMER was successful in developing communication (86.4\% of respondents; Fig. 3), and facilitating engagement within an interdisciplinary context, but that synthesis was perceived to be less successful (54.5\% of respondents; Fig. 3). Early-career workshops (86.4\% of respondents; Fig. 4a), annual meetings (68.2\% of respondents; Fig. 4a), and research visits to other institutions (40.9\% of respondents; Fig. 4a) were perceived to be the most effective learning activities, whereas courses $(27.3 \%$ of respondents; Fig. 4a), self-direction $(22.7 \%$ of respondents; Fig. 4a) and coursework and other opportunities $(22.7 \%$ of respondents; Fig. 4a) were considered by survey participants to be the least effective, facilitating less communication (Fig. 4b).

NorMER's facilitation of interdisciplinary outputs (e.g. peer-reviewed publications) and originality were reported to be a success (Fig. 5a). Increased understanding of interdisciplinarity was perceived

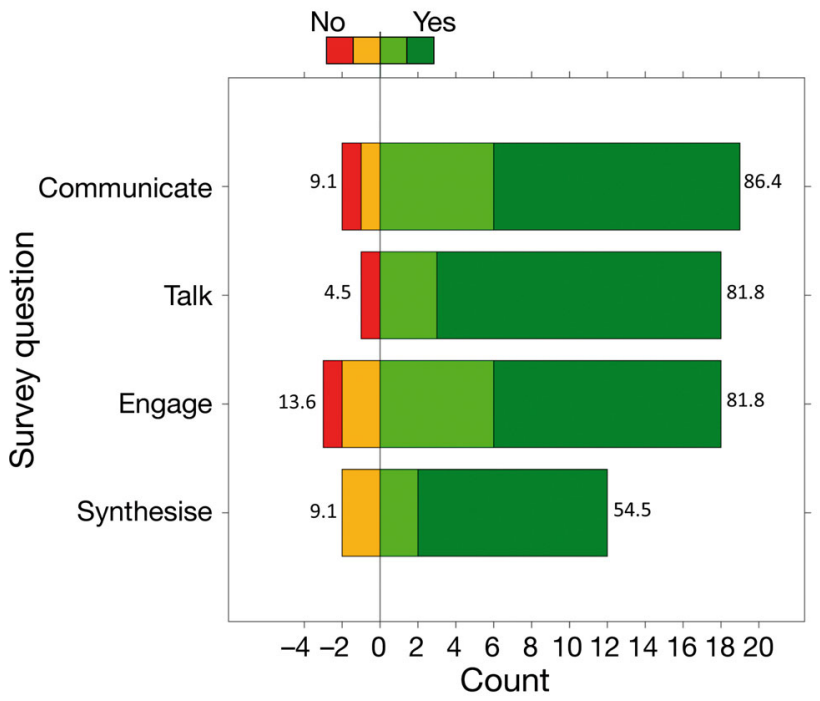

Fig. 3. Evaluation of how well Nordic Centre for Research on Marine Ecosystems and Resources under Climate Change (NorMER) experiences have enabled interdisciplinary learning. Colours and response rate explanation same as in Fig. 2

across more than two-thirds $(68.2 \%)$ of the earlycareer researchers (Fig. 5b). Similarly, integration of interdisciplinary knowledge was seen to have been achieved through collaboration $(100 \%$ of respondents; see group of questions marked 'A' in Fig. 6), and communication with other disciplines (86.4\% of respondents; group A in Fig. 6). Participants thought that both their knowledge of and curiosity about interdisciplinarity increased due to participation in

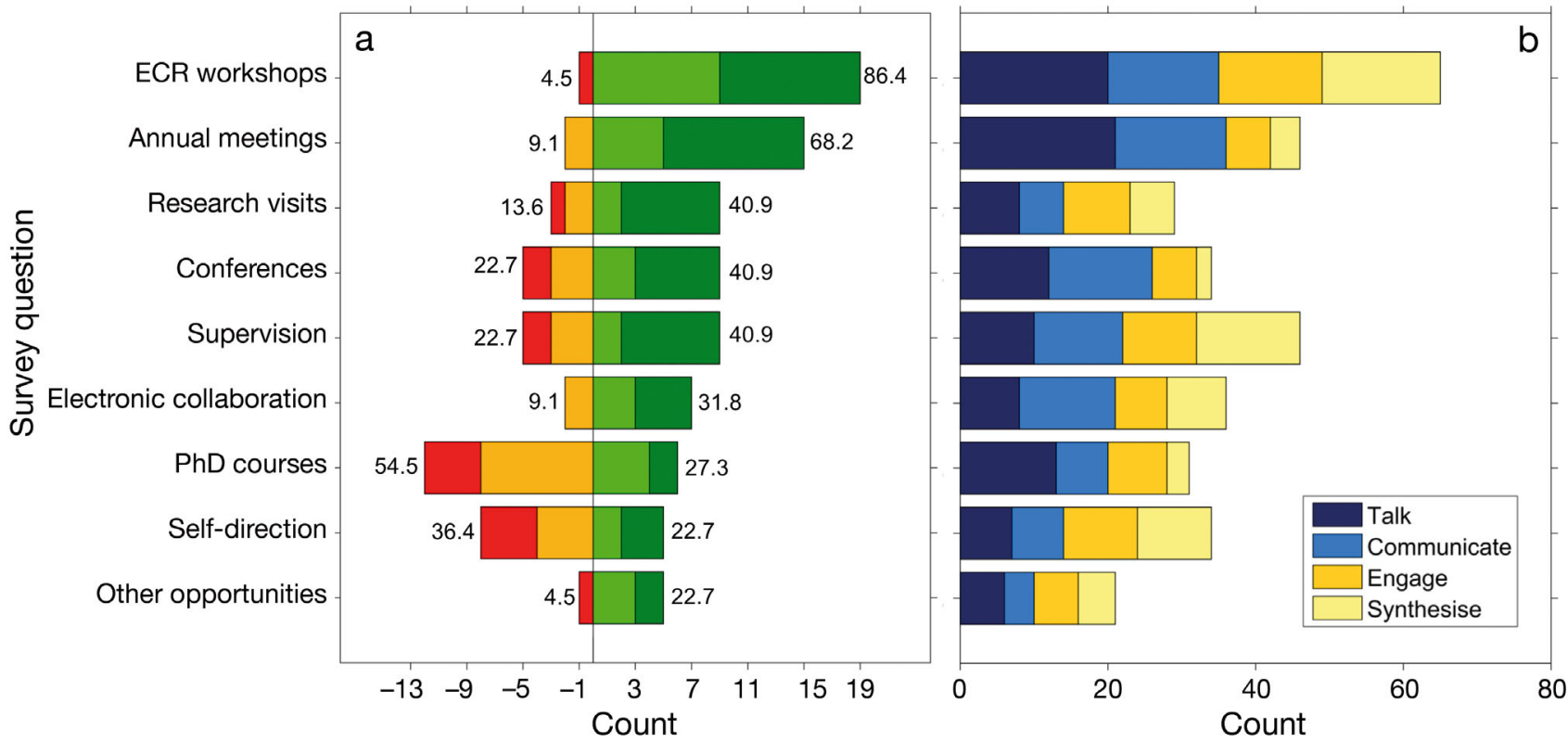

Fig. 4. (a) Interdisciplinary learning process activities. Colours and response rate explanation same as in Fig. 2 . ECR = earlycareer researcher. (b) Associated learning theme for each learning process activity in panel (a). Counts exceed 22 as individuals could select $>1$ learning theme (see Section III in the Supplement at www.int-res.com/articles/suppl/c074p121_supp.pdf) 

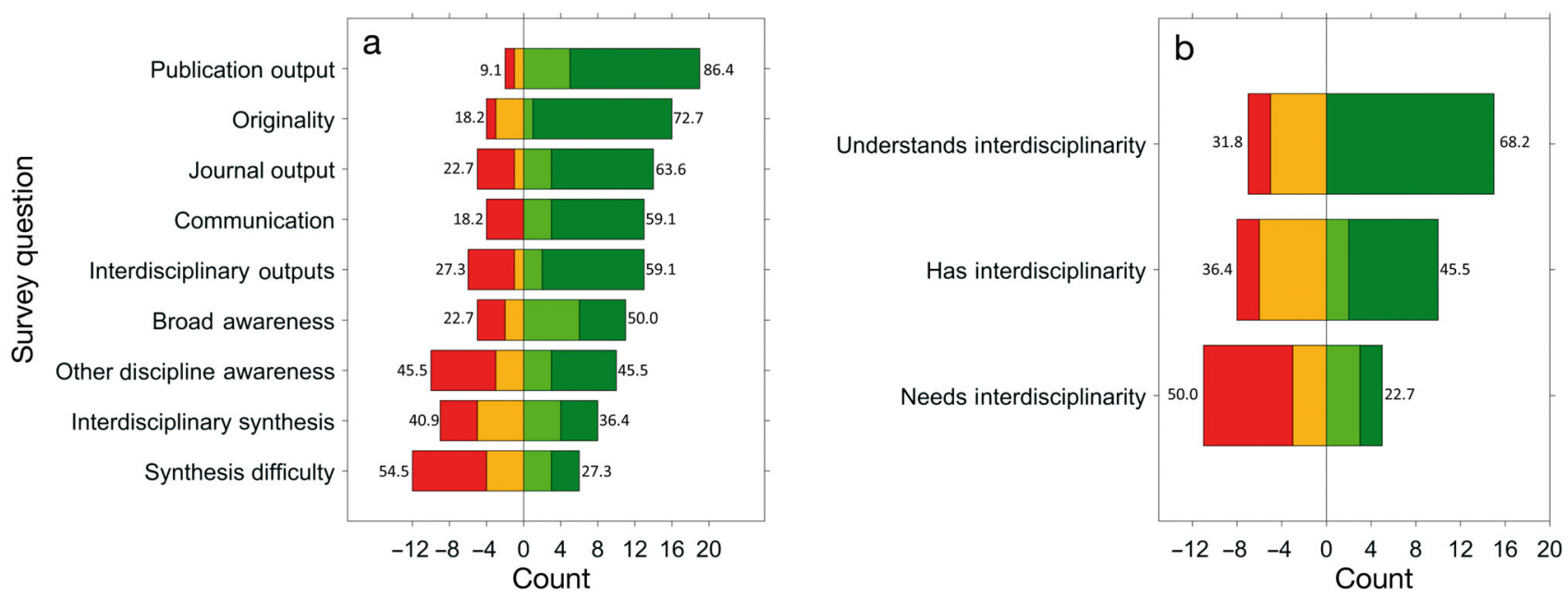

Fig. 5. (a) Evaluation of Nordic Centre for Research on Marine Ecosystems and Resources under Climate Change (NorMER) dissertation and publications. (b) Evaluation of interdisciplinarity with regard to NorMER position (PhD/postdoc) and publications. Colours and response rate explanation same as in Fig. 2

NorMER $(86.4$ and $77.3 \%$ of respondents respectively; group A in Fig. 6).

Overall, NorMER was positively evaluated by survey participants to have improved interpersonal skills, such as openness to criticism (63.6\% of respondents; see group of questions marked 'B' in Fig. 6), patience, diligence, as well as more difficult interdisciplinary skills, including evaluation of disciplinarity (72.7\% of respondents; group B in Fig. 6) and inte-

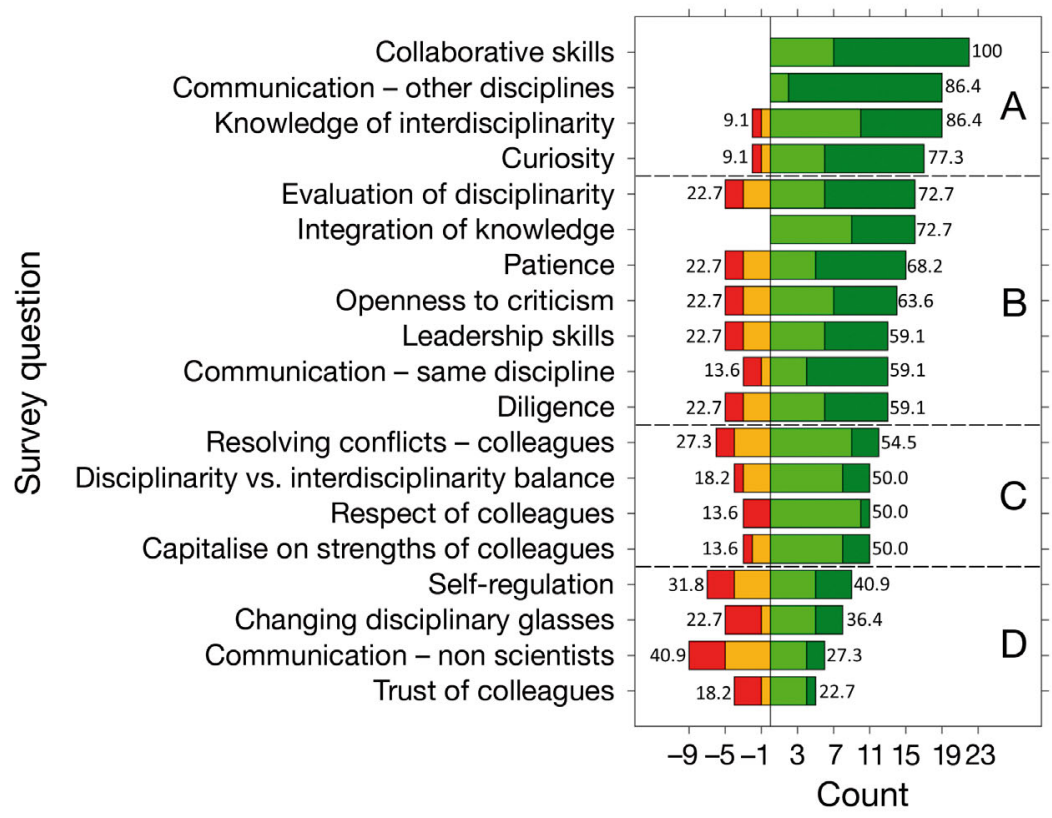

Fig. 6. Skills improved due to participation in Nordic Centre for Research on Marine Ecosystems and Resources under Climate Change (NorMER). Colours and response rate explanation same as in Fig. 2. Dashed lines indicate groups of questions that show increasing strength of positive responses from top to bottom (labelled A-D) gration of knowledge $(72.7 \%$ of respondents; group B in Fig. 6). Even challenging interpersonal skills were still evaluated positively by survey participants, such as the ability to resolve conflicts and achieve balance between disciplinarity versus interdisciplinarity, although they were reported to a lesser extent (group C in Fig. 6). Some skills, however, were not evaluated positively, i.e. a Likert score of $<3$, such as self-regulation $(31.8 \%$ of respondents, albeit with $40.9 \%$ responding positively; group D in Fig. 6) and communication with 'non-scientists' $(40.9 \%$ responding negatively; group D in Fig. 6).

\subsection{NorMER's effectiveness as an interdisciplinary research network}

The vast majority of project participants felt that NorMER generally improved interdisciplinarity within their research, benefiting participants' future disciplinary or interdisciplinary careers. On the whole, however, not all aspects of interdisciplinarity were achieved. Critical assessment and synthesis for example were suggested to have been achieved to a lesser extent, which is not surprising given the duration of NorMER (5 yr). The NorMER case study should thus be thought of as a partially successful interdisciplinary network, or one that spans interdisciplinary, trans-discipli- 
nary ('integrates the natural, social and health sciences in a humanities context and transcends their traditional boundaries'; Alvargonzalez 2011, p 388), as well as multi-disciplinary ('draws on knowledge from different disciplines but stays within their boundaries'; Alvargonzalez 2011, p 388) researchers (Choi \& Pak 2006, Alvargonzález 2011).

\subsection{Limitations}

With any methodology, there are benefits and disadvantages. We focus on an indirect assessment method (Allen 2007) to try and evaluate the effectiveness of and lessons learned from NorMER. By the very nature of this self-reflexive approach, no control sample or survey could be used and thus evaluated against the final results. In addition, we are open to a level of subjectivity, not only as authors of this paper, but as NorMER participants. Therefore, the results of the survey cannot be considered as a fully objective evaluation. Nevertheless, using the observer's selfevaluation, we gain insight and knowledge useful for understanding the perceived effectiveness of approaches (including, but not limited to, interdisciplinarity) that are difficult to evaluate with formal tests. Analysing perceived effectiveness is an essential step towards awareness of our own reflective learning patterns and subsequent decision to apply them consciously in our research careers (Boyd \& Fales 1983).

\subsection{Avoiding pitfalls in interdisciplinary education}

In NorMER, it cannot be claimed that collectively all early-career researchers avoided all pitfalls of performing interdisciplinary research, but results suggest more awareness of interdisciplinarity as well as the gained acquisition of the skills needed to perform future interdisciplinary and collaborative research. The first pitfall that we listed in Section 1.2 above, disjointed communication, can be more easily recognised and addressed, as collaborative and communicative skills were perceived to have improved. The second and fifth pitfalls, absence of credibility frameworks and lack of continuity, are both still a relevant issue while discussing joint research papers in early-career self-directed workshops and attempting to publish interdisciplinary outputs (i.e. side projects). We also continue to struggle with the third pitfall: identifying focal themes and audiences. Not everyone had the desire to become an interdisciplinary re- searcher, as this also relies on personal character, inclinations and what jobs are available (fifth pitfall: lack of continuity). Side projects have become, in our experience, the main route by which interdisciplinary skills have been achieved. However, we have found that despite our abilities to overcome disjointed communication through such side projects, there is no way to avoid trade-offs with time constraints. Accordingly, focusing on skills such as balance and selfregulation as well as courses aimed at increasing these could be areas of improvement (Fig. 6).

Project management was particularly forwardthinking in addressing the fourth pitfall, which indicates that interdisciplinary education must go on despite a dearth of criteria for evaluation. We found that to develop interdisciplinary collaboration as a transferable skill, it is more effective to remove hierarchies, so that interpersonal skills have a greater chance of developing in a peer-peer environment, where they will be needed in future research endeavours.

\subsection{Benefits gained from early-career self-directed workshops}

Since early-career workshops are not often used in other interdisciplinary research networks, but proved to be particularly effective learning tools in NorMER, we describe here some of the lessons learned from participation in such workshops. In our experience, successful interdisciplinary collaboration relies upon the initiative and motivation of the students to establish a cohesive group. This non-hierarchical interactive experience stimulated professional collaborative endeavours, thereby aligning the educational experience with programme goals. However, collaboration is not easy. The following guidelines can help other researchers (in all career stages) to generate interdisciplinary research more efficiently and effectively and foster successful scientific collaborations in general.

\subsection{Guidelines for interdisciplinary research}

A voluntary approach is imperative. To achieve voluntary commitment, it is pivotal that everyone has a well-defined role in the project, so that the perceived payoff is worthy of each participant's time and effort. Payoffs in our experience included co-authorship, opportunities to learn new methods and ways of thinking, and forming an open social and professional circle. 
Clear goals should be defined, as well as how to reach them. In a multidisciplinary group, formulating joint goals is as challenging as it is important. Miscommunication can happen easily regarding project ideas or perceived responsibilities, thereby hindering progress. To avoid miscommunication, enough time should be planned for finding a common 'vocabulary' across disciplines, in which the goals and the project plan are formulated. Furthermore, it is important that the group acknowledges and agrees upon the tasks and goals that can be realistically achieved within a given time frame.

Patience is crucial. Hashing out differences in opinions among participants and orienting newcomers to established objectives and activities can lead to long, painstaking discussions. Nevertheless, it can save time by challenging each other to focus on the most interesting and achievable ideas, achieving a common ground of credibility (Öberg 2009).

Knowledge sharing and project guidance from senior researchers will lead to better judgements. Useful guidance spanned from whether the project is efficient and feasible to providing advice for improvements. In addition, moral support from senior scientists and finances provided by NorMER were imperative to facilitate the extra time needed to establish momentum.

Uneven workloads need to be accepted. Individual availability varies with personal circumstance. Therefore, even though achieving equality in workload is impossible, achieving equality as a group member is not: nobody should feel penalised or outcast for not being able to participate. It is helpful to negotiate rules of engagement beforehand, so that expected responsibilities and authorship are agreed upon.

Leadership maintains momentum. This is important when the project participants are spread out geographically and unable to have regular meetings in person. To ensure persistence, it is imperative that at least 2 or 3 individuals accept responsibility for the extended burdens of setting deadlines, and managing the project.

\subsection{Implications for other research networks and beyond}

This study sheds light on the important topic of interdisciplinarity, how it may be achieved within a doctoral research network setting, as well as how to navigate around common pitfalls which can hinder success. Several lessons have been learned through participation in NorMER, that are applicable to other projects aimed to establish early-career researchers, such as the importance of setting clarified common goals and objectives, and how to reach them through knowledge sharing and project guidance. We have found that voluntary participation, patience, acknowledging what is manageable, setting clear rules of engagement as well as leadership that maintains momentum are all crucial in starting and completing successful interdisciplinary endeavours. Although this is common-sense knowledge that applies to scientific collaboration in general, these insights are seldom included at the beginning of a research project, causing frustration and friction when it comes to authorship and credibility towards the end. This study provides information and guidelines on how to approach interdisciplinarity, avoiding such pitfalls from the start. As such, these guidelines, knowledge and information have wider implications beyond the assessment of NorMER itself, and are not only important for the design of other doctoral education programmes and research networks, but also for interdisciplinary research, science collaboration and the broader academic community in general.

\section{CONCLUSIONS}

Interdisciplinary research within doctoral education is full of caveats, but many are not due to differences among disciplines. The most effective remedies concern how - not what - knowledge is transferred and the willingness of actors to collaborate.

In this respect, we have learned 3 important lessons from our collective experience. (1) It should not be a requirement that every early-career scientist become an interdisciplinary researcher. It is more valuable to gain the necessary communication and collaborative skill set to be able to work in an interdisciplinary manner when needed. (2) Interpersonal skills must be considered of equal importance as disciplinary depth or breadth, e.g. less effective learning tools (e.g. disciplinary courses) could be replaced with ones that focus on more difficult interpersonal skills (e.g. balance and self-regulation). (3) There is a need for trade-offs to be explicitly chosen a priori, i.e. when designing interdisciplinary doctoral education programmes.

Acknowledgements. This study is a product of the Nordic Centre for Research on Marine Ecosystems and Resources under Climate Change (NorMER, Project no. 36800), which is funded by the Norden Top-level Research Initiative subprogramme 'Effect Studies and Adaptation to Climate 
Change'. We thank Nils Chr. Stenseth for support during the preparation of this manuscript, as well as 3 anonymous reviewers for useful and constructive comments.

\section{LITERATURE CITED}

Allen MJ (2007) Assessing academic programs in higher education. Anker Publishing Company, Boston, MA

Allen I, Seaman CA (2007) Likert scales and data analyses. Qual Prog 40:64-65

Alvargonzález D (2011) Multidisciplinarity, interdisciplinarity, transdisciplinarity, and the sciences. Int Stud Philos Sci 25:387-403

Boden D, Borrego M, Newswander LK (2011) Student socialization in interdisciplinary doctoral education. High Educ 62:741-755

Boonstra WJ, Ottosen KM, Ferreira ASA, Richter A and others (2015) What are the major global threats and impacts in marine environments? Investigating the contours of a shared perception among marine scientists from the bottom-up. Mar Policy 60:197-201

Borrego M, Cutler S (2010) Constructive alignment of interdisciplinary doctoral curriculum in an analysis of successful IGERT proposals. J Eng Educ 99:355-369

Borrego M, Newswander L (2011) Analysis of interdisciplinary faculty job postings by institutional type, rank and discipline. J Professoriate 5:1-34

Boyd E, Fales A (1983) Reflective learning: key to learning from experience. J Humanist Psychol 23:99-117

Bromham L, Dinnage R, Hua X (2016) Interdisciplinary research has consistently lower funding success. Nature 534:684-687

Choi BC, Pak AW (2006) Multidisciplinarity, interdisciplinarity and transdisciplinarity in health research, services, education and policy. 1. Definitions, objectives, and evidence of effectiveness. Clin Invest Med 29:351-364

Haapasaari P, Kulmala S, Kuikka S (2012) Growing into interdisciplinarity: how to converge biology, economics and social sciences in fisheries research. Ecol Soc 17:6

Haider LJ, Hentati-Sundberg J, Giusti M, Goodness J and others (in press) The undisciplinary journey: early-career perspectives in sustainability science. Sustain Sci, doi: 10.1007/s11625-017-0445-1

Lattuca LR (2002) Learning interdisciplinarity: sociocultural perspectives on academic work. J High Educ 73:711-739

Kozano LM, García-Cueto E, Muñiz J (2008) Effect of the number of response categories on the reliability and

Editorial responsibility: Mauricio Lima,

Santiago, Chile validity of rating scales. Methodology 4:73-79

Kyall C, Bruce A, Marsden W, Meagher L (2013) The role of funding agencies in creating interdisciplinary knowledge. Sci Public Policy 40:62-71

Manathunga C, Lant P, Mellick G (2006) Imagining an interdisciplinary doctoral pedagogy. Teach High Educ 11: 365-379

Mitchell C, Willetts J (2009) Quality criteria for inter-and trans-disciplinary doctoral research outcomes. Institute for Sustainable Futures, University of Technology, Sydney (UTS)

*Mooney HA, Duraiappah A, Larigauderie A (2013) Evolution of natural and social science interactions in global change research programs. Proc Natl Acad Sci USA 110: 3665-3672

Morse WC, Nielsen-Pincus M, Force JE, Wulfhorst JD (2007) Bridges and barriers to developing and conducting interdisciplinary doctoral-student team research. Ecol Soc 12:8

NIH (National Institutes of Health) (2009) Common Fund strategic planning report. NIH, Bethesda, MD. https:// commonfund.nih.gov/sites/default/files/Common_Fund _Strategic_Planning_Report_2009.pdf

NSF (National Science Foundation) (2011) Empowering the nation through discovery and innovation: NSF strategic plan for fiscal years (FY) 2011-2016 (No. NSF 11-047). NSF, Arlington, VA. www.nsf.gov/news/strategicplan/ nsfstrategicplan_2011_2016.pdf

Öberg G (2009) Facilitating interdisciplinary work: using quality assessment to create common ground. High Educ 57:405-415

*Pedersen MW, Kokkalis A, Bardarson H, Bonanomi S and others (2016) Trends in marine climate change research in the Nordic region since the first IPCC report. Clim Change 134:147-161

Punch KF (2014) Introduction to social research, quantitative \& qualitative approaches, 3rd edn. SAGE Publications, London

* Shaman J, Solomon S, Colwell RR, Field CB (2013) Fostering advances in interdisciplinary climate science. Proc Natl Acad Sci USA 110:3653-3656

Spelt EJH, Biemans HJA, Tobi H, Luning PA, Mulder M (2009) Teaching and learning in interdisciplinary higher education: a systematic review. Educ Psychol Rev 21: 365-378

Stenseth NC, Mysterud A, Durant JM, Hjerman DØ, Ottersen G (2005) Uniting ecologists into a smooth, tasty and potent blend. Mar Ecol Prog Ser 304:289-292

Submitted: February 22, 2017; Accepted: September 12, 2017 Proofs received from author(s): December 1, 2017 